\title{
Electromagnetic Finite Element Design of Axial Flux Permanent Magnet Machines for Low Speed Applications
}

\author{
Ângela P. Ferreira, Artur F. Costa
}

\begin{abstract}
The higher torque to volume ratio of Axial Flux Permanent Magnet (AFPM) machines, when compared with their radial flux counterparts, is enhanced in multi pole design, making them suitable for low speed applications. This paper presents a comprehensive approach to the finite element-aided electromagnetic design of a double-sided AFPM machine with internal rotor. The Finite Element (FE) model is included in a coupled electromagnetic-thermal design procedure. Special attention is given to leakage fluxes, synchronous and armature reaction inductances and no-load electromotive force computation. The evaluation of the FE model routine of the design procedure is performed through experimental validation of a prototype machine.
\end{abstract}

Index Terms-Finite Element Model; Axial Flux Permanent magnet machines; Inductances.

\section{INTRODUCTION}

A xial Flux Permanent Magnet (AFPM) machines are very well suited for low speed applications due to their higher torque to volume ratio in multi-pole solutions [1]. The axial length of the machine is dependent on the flux density in the rotor and/or stator yokes. Thus, in opposition to radial flux machines, both stator and rotor yokes can be fully utilized. As a consequence, the radial active length of the axial flux machine remains almost unchanged, but the axial length can decrease, resulting in a higher torque density than their counterparts based on radial flux. Additionally, the flat structure of AFPM machines simplifies the Permanent Magnet (PM) manufacturing process, allowing a reduction of mass production costs, balancing, in some extent, the increasing prices of rareearth PM $[2,3]$.

AFPM machines can be single- or double-sided, with or without armature slots, have internal or external rotor, in which PM may be buried or surface mounted. The doublesided AFPM machine is the most promising and widely used [4-6]. This topology has the advantage of eliminating axial forces between PM and the stator iron and also presents the benefit of increasing the total air gap surface. Moreover, the inner part structure of the double-sided topology may be non-ferromagnetic, which reduces total weight. The internal rotor arrangement uses fewer PM at the expense of winding, and simplifies the construction process by easily fixing the stator structure to the machine frame.

In low speed machines, resistive losses are dominant when compared with mechanical and iron losses, due to their low main electrical frequency. Double-sided topology with inner rotor favours the cooling process because the main heat source is located near the frame of the machine.

If external rotor topology is used, with PM in a Halbach

A. P. Ferreira is with Polytechnic Institute of Bragança and CISE Electromechatronic Systems Research Centre, UBI, Portugal (e-mail: apf@ipb.pt).

A. F. Costa is with the Department of Electrical Engineering, FEUP, Portugal (e-mail: acosta@fe.up.pt). array [7], all structure may be obtained without ferromagnetic cores.

The machine performance is, in a large extend, dictated by the electromagnetic and thermal designs. In fact both designs are interrelated and cannot be dissociated $[8,9]$. This issue is particularly important with the increasing requirements for energy efficiency and cost reduction in machinery design with non classical topologies as the AFPM machines. The mandatory interaction between the electromagnetic and thermal behaviour of an electrical machine is strongly related with the losses directly linked to the quantity of heat to be removed in steady-state condition.

The use of design tools based on Finite Element (FE) methodologies has gained popularity and importance in last decades [10-13]. FE modelling does not replace the analytical project, but complements it with a detailed approach, highlighting local events or hazardous saturation gradients, e.g., hardly noticeable without practical experimentation. Simply put, the analytical project allows a macro solution of the machine design, while analysis based on FE modelling provides a micro perspective of the design.

This paper presents a comprehensive approach to the finite element-aided electromagnetic design of a doublesided AFPM machine with internal rotor. This routine is included in a coupled electromagnetic-thermal design procedure, of which computation of thermal model, by means of a lumped-parameter equivalent circuit, was reported on [8].

Next section presents basic design choices of the AFPM machine and the initial sizing estimates, based on general sizing equation and analytical procedures for magnetic and electrical loading [14]. Section III presents the FE model of the machine and in section IV the validation of the design procedure is accomplished through experimental tests of a prototype machine. Finally, there are drawn the main conclusions of the paper.

\section{AFPM MACHINE TOPOLOGY AND MAIN DIMENSIONS}

The AFPM multi-pole machine prototype investigated is a double-sided with internal rotor structure and slotted stators, shown in Fig. 1. The potential application of the machine is in small-scale direct-driven wind generation systems [2, 15].

For a given amount of PM material, slotted stators increase remarkably the amplitude of the airgap flux density due to shorter airgap. Slotting reduces the required amount of permanent magnets, which yields savings in the generator price but, on the other hand, it may cause undesired torque pulsations. The adopted structure allows the rotation of one stator over one half of the slot pitch with respect to the other, which results in reduced slot ripple and space harmonic components [16], although this technique has not been implemented in the FE model nor in the experimental prototype. A conventional three-phase 
distributed winding, with one slot per pole and phase, was adopted.

For the adopted structure, PM may be located on the surface or inside the rotor disk. Thereby, the main flux may flow axially through the rotor disk or flow circumferentially along the rotor disk. The chosen solution uses PM located at the surface of the rotor disk. Doing so, it is not necessary a ferromagnetic rotor core and the axial length is substantially reduced, which consequently improves the power density of the machine.

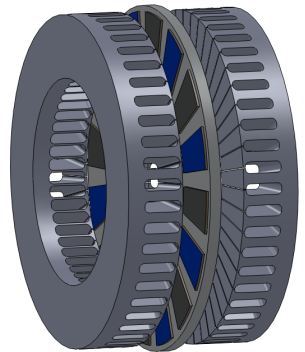

Fig. 1. AFPM multi-pole machine topology (double-sided with internal rotor structure).

Table I summarizes the main parameters of the multipole AFPM machine based on general sizing equations and analytical procedures.

TABLE I

MAIN DiMENSIONS OF THE AFPM MACHINE PROTOTYPE

\begin{tabular}{lc}
\hline PARAMETER & VALUE \\
\hline Axial motor length & $5,62 \mathrm{~cm}$ \\
\hline Stator yoke length & $0,86 \mathrm{~cm}$ \\
\hline Airgap thickness & $0,5 \mathrm{~mm}$ \\
\hline Inner radius of the stator iron & $6,5 \mathrm{~cm}$ \\
\hline Outer radius of the stator iron & $9 \mathrm{~cm}$ \\
\hline Permanent magnet axial length & $1 \mathrm{~cm}$ \\
\hline Pole-arc coefficient & 0,6 \\
\hline Number of pole pairs & 10 \\
\hline Pole pitch (at average radius) & $2,49 \mathrm{~cm}$ \\
\hline Number of phases & 3 \\
\hline Number of coils per stator & 60 \\
\hline Number of turns per phase and per stator & 480 \\
\hline Number of slots per pole and phase & 1 \\
\hline Rated speed & $600 \mathrm{rpm}$ \\
\hline Rated power & $700 \mathrm{~W}$ \\
\hline Remanent magnetic flux density of PM & $1,12 \mathrm{~T}$ \\
\hline Linear current density (at inner radius) & $13,4 \mathrm{kA} / \mathrm{m}$ \\
\hline $\begin{array}{l}\text { RMS no-load phase to neutral voltage per stator } \\
\text { (at 600 rpm) }\end{array}$ & $72,5 \mathrm{~V}$ \\
\hline
\end{tabular}

\section{FE MODELLING}

The adopted recursive design procedure, uses a twodimensional FE approach. This analysis does not allow modelling border phenomena in the internal and external radii of the machine, as well as asymmetries that may exist by variation of the pole width along the active part. Consideration of these aspects, from an integrated point of view, requires $3 \mathrm{D}$ modelling, for which pre-processing and computation are too time consuming. From the perspective of the design procedure explored here, where it is required an interaction between the design procedure and the geometry of the machine, this is not considered practical. Alternatively, 2D FEM analysis was conducted using multiple computational planes $(i=1, \ldots, N$ in the formulation below) in the radial direction. This quasi-3D approach allows the inclusion of effects requiring that extent. For the geometry under analysis, and after a sensitivity analysis, three computational planes were used.

FE model also explores the symmetry condition over the axial direction, by using homogeneous Neumann boundary condition, setting the nullity of the tangential component of the magnetic field. The recurrence with respect to a pole pair or pole pitch is established by using even or odd periodic conditions, respectively. Homogeneous Dirichlet condition is applied to the physical frontier of the machine, by assigning the magnetic vector potential component $A_{z}$ to zero. Boundary conditions of the model are shown in Fig. 2.

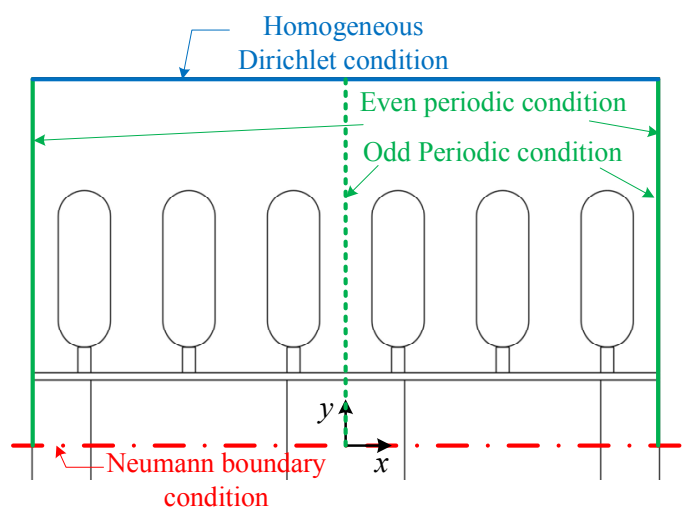

Fig. 2. Boundary and symmetry conditions for 2D FE analysis.

The problem is time dependent due to rotational motion which can be achieved by setting a boundary in the air gap defining two distinct domains, one supporting the rotor and the other the stator. Rotor and stator meshes are distinct, but coupled by an appropriate transformation that ensures continuity of magnetic vector potential in the fixed coordinate system. A magnetostatic analysis, with perpendicular induction currents and magnetic vector potential, together with appropriate post-processing techniques allows the exploitation of varying parameters in the performance of the machine: saturation degree into the machine, PM and airgap leakage fluxes, computation of synchronous and armature reaction inductances, mutual inductance between two stators, electromotive force and also electromagnetic and cogging torques. The model is carried out through COMSOL Multiphysics software, AC/DC module [17]. The following sub-sections presents the main results obtained for the configuration under analysis.

\section{A. Magnetic flux density}

Distribution of the magnetic flux density in the average radius, for no-load and load conditions, are presented in Fig. 3.

Numerical values overlapping the picture are the results from the analytical approach, obtained by means of a reluctance network, which are in agreement with the numerical solution.

The airgap magnetic flux density is shown in Fig. 4. From the analysis of the wave form in load condition, it is possible to verify that the non-uniform distribution of the magnetic flux density in the teeth causes an asymmetry in the wave form and also that the armature reaction is 
negligible, as expected in a structure with surface mounted PM, due to its larger equivalent air gap.

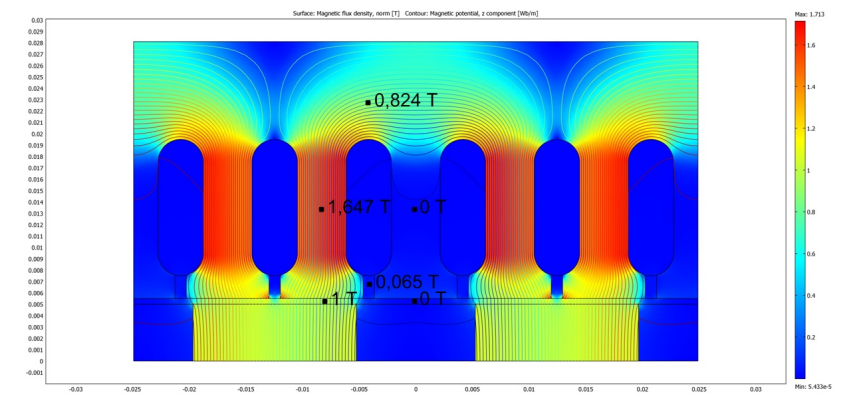

(a)

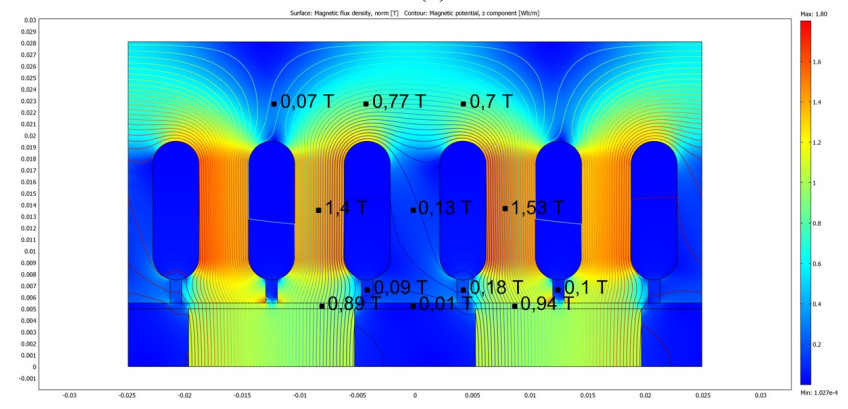

(b)

Fig. 3. Magnetic flux density in the average radius of the machine for (a) no-load and (b) load conditions.

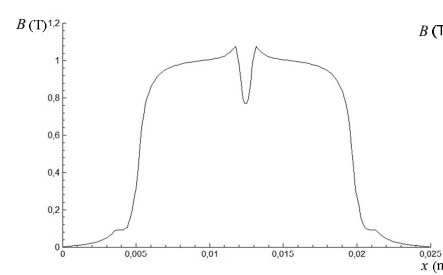

(a)

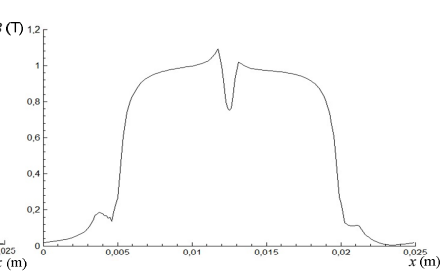

(b)
Fig. 4. Air gap magnetic flux density in the average radius of the machine for (a) no-load and (b) load conditions.

\section{B. PM and air gap leakage fluxes}

The analysis of the leakage flux between adjacent PM, and leakage from the flux that crosses the air gap, in noload condition, is realized for the air gap flux path of maximum and minimum reluctance, as shown in Fig. 5 (a) and (b), respectively.

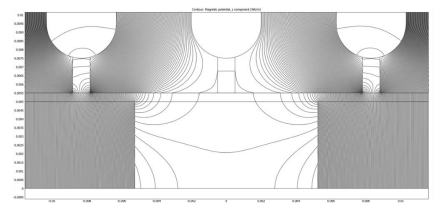

(a)

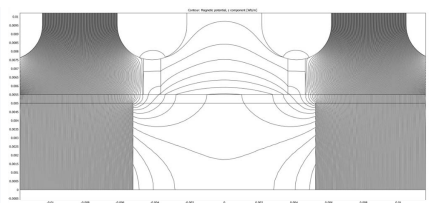

(b)
Fig. 5. PM and air gap leakage fluxes through (a) flux path of maximum reluctance and (b) flux path of minimum reluctance.

The PM leakage flux, evaluated by the ratio between the air gap flux in a pole pitch and the magnetic flux in the borders of the PM, is about $15 \%$. Regarding the airgap leakage flux, it is evaluated by the ratio between the magnetic flux in the cross-section of the teeth and the one in the airgap, along a pole pitch. The reluctance variation does not have a significant contribution to the airgap leakage flux, being $13,7 \%$ for minimum reluctance path and $11 \%$ for maximum reluctance path.

\section{Inductances}

The determination of the inductances is made through a magnetostatic analysis, whereas the PM contribution is cancelled $\left(B_{r}=0\right)$, considering only the armature reaction is considered. Current densities in the slots are adjusted for $i_{d(q)}=I_{\max }$ and $i_{q(d)}=0$, for longitudinal (transversal) synchronous inductances, $L_{s d(q)}$. From the numerical solution, synchronous inductances may be obtained through the magnetic energy stored in the structure or through the linkage flux. Due to the non linearity of the magnetic circuit, the last one is preferred, and given by

$$
L_{s d(q)}=\frac{\lambda_{I d(q)}}{i_{d(q)}}=\frac{\lambda_{a}}{I_{\max }}
$$

where $\lambda_{I d(q)}$ is the linkage flux produced by the armature in the $d(q)$ axis, i.e., the linkage flux in the phase $a, \lambda_{a}$, whose axis is coincident with $d(q)$ axis, respectively, given by

$$
\lambda_{a}=N_{f} \frac{2}{S_{r}} \sum_{i=1}^{N} \Delta r_{i} \int_{S_{r}} A_{z i} d s
$$

being $N_{f}$ the number of turns per phase, $S_{r}$ the cross section of a slot, $\Delta r_{i}$ the radial length and $A_{z i}$ the magnetic vector potential, both in the computational plane $i$.

Armature reaction inductances, $L_{m d(q)}$, can be determined through the axial component (i.e., the $y$ component) of the air gap magnetic flux density due to the armature reaction in the average computation plan, through the maximum linkage flux per pole, given by

$$
\lambda_{d(q)}=k_{w} N_{f} \frac{2}{\pi} B_{\max I, d(q) 1} \frac{\pi}{2 p}\left(r_{\text {out }}^{2}-r_{\text {in }}^{2}\right)
$$

where $k_{w}$ is the winding factor for fundamental component, $p$ is the pole pair number, $r_{\text {in(out) }}$ is the inner (outer) radius of the stator core and, finally, $B_{\max I, d(q) 1}$ is the amplitude of the fundamental air gap magnetic flux density due to the armature reaction in $d(q)$ axis, respectively, obtained by a Fast Fourier Transform (FFT) algorithm, shown in Fig. 6.

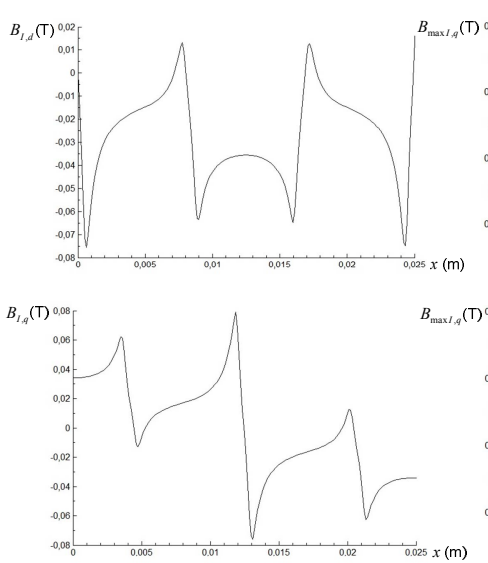

(a)

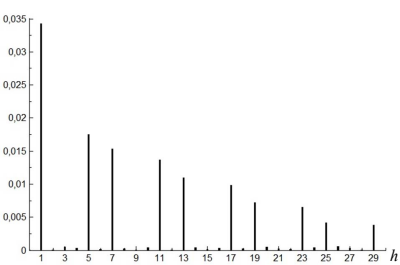

Fig. 6. Air gap magnetic flux density in the $d(q)$ axis; (a) wave form over a pole pitch. (b) FFT.

The linkage flux given by (2) includes leakage fluxes in the slots and in the air gap, and also the harmonic content of 
the armature reaction, but these quantities are absent in the formulation proposed by (3). Thus, the difference between synchronous inductances and armature reaction inductances represent the leakage stator inductance, $L_{l k}$, which includes slot and differential leakage inductances:

$$
L_{l k}=L_{s d(q)}-L_{m d(q)}
$$

Alternatively, the leakage stator inductance can also be computed from the magnetostatic numerical solution, evaluating the magnetic vector potential in a slot, as shown in Fig. 7.

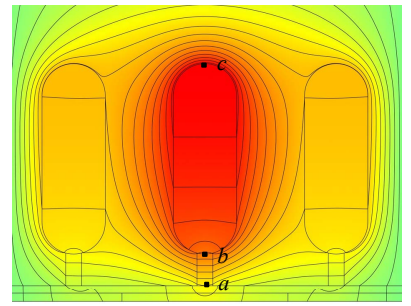

(a)

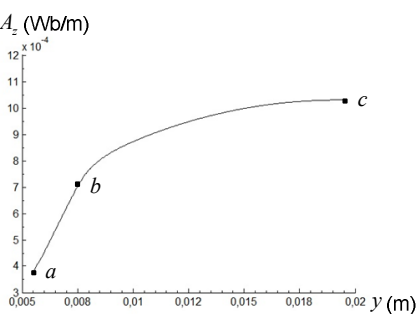

(b)
Fig. 7. (a) Slot leakage flux; (b) magnetic vector potential in the boundary of the slot.

Leakage flux has two different paths: one through the slot opening (from $a$ to $b$ ) and the other in the slot itself (between $b$ and $c$ ). The contribution of this two paths to the leakage flux in a slot, $\phi_{r, l k}$, is given by

$$
\phi_{r, l k}=\sum_{i=1}^{N}\left(\frac{\Delta r_{i}}{\Omega} \int_{0}^{\Omega} A_{z i} \partial \Omega-\Delta r_{i} A_{z, a i}\right)
$$

where $\Omega$ is the boundary between the slot and the stator iron ( $b$ to $c$ ) and $A_{z, a}$ is the magnetic vector potential in point $a$. Using (5), the leakage stator inductance, is computed by

$$
L_{l k}=\frac{2 N_{f}}{I_{\max }} \phi_{r, l k}
$$

It should be noted that both approaches given by (4) and (6), neglect the end winding leakage inductance. As mentioned previously, modelling border phenomena, such as end winding contribution, is only possible within a $3 \mathrm{D}$ approach or, in alternative, through empirical formulae, as proposed in [5].

Regarding the mutual inductance between individual stators, $M$, it can be computed from the numerical solution of one pole pair over the total axial length of the machine, as presented in Fig. 8.

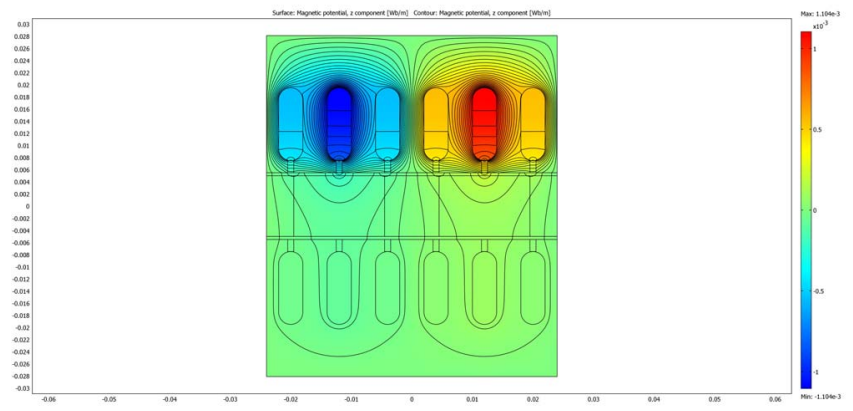

Fig. 8. Magnetic vector potential over one pole pair of the machine including both stators. Currents in the upper stator are settled to $i_{q}=I_{\max }$ and $i_{d}=0$.

Current densities in the slots of one stator are adjusted for $i_{d(q)}=I_{\max }$ and the mutual inductance is evaluated through the ratio between the linkage magnetic flux in the other stator and $I_{\max }$. The reluctance between the two stators of the adopted topology is considerably high, from which the computed mutual inductance is negligible.

The results obtained from above methodologies for the different inductances are presented in Table II.

TABLE II

COMPUTED INDUCTANCES (mH)

\begin{tabular}{ccccccc}
\hline$L_{s d}$ & $L_{s q}$ & $L_{m d}$ & $L_{m q}$ & \multicolumn{2}{c}{$L_{l k}$} & $M$ \\
& & & & $(4)$ & $(6)$ & \\
\hline 6,95 & 6,92 & 1,98 & 1,94 & 4,97 & 4,34 & 0,58 \\
\hline
\end{tabular}

The magnetic circuit of the adopted machine configuration is practically isotropic, from which direct and quadrature inductances are similar. Nevertheless, due to the presence of the PM in the direct axis $\left(\mu_{r}=1,05\right)$, inductances in the $d$-axis are slightly larger than the ones in $q$-axis.

\section{Influence of the stator iron saturation level}

The non-linearity of the magnetic material of the stator influences the values of inductances, by varying the permeability of the ferromagnetic iron.

Under load condition, due to the presence of PM flux, the stator iron saturation level is significantly higher than the considered in previous situations, whereas magnetic flux density was only due to armature reaction. This can be displayed with the aid of the relative permeability of the stator iron under both conditions (Fig. 9 and Fig. 10)

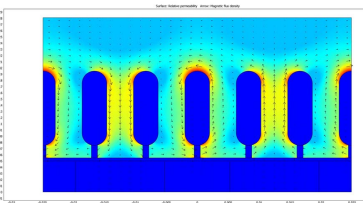

(a)

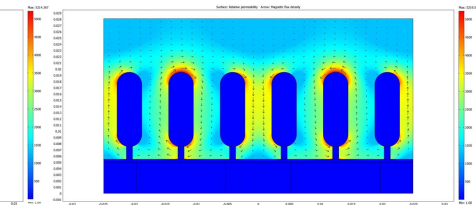

(b)
Fig. 9. Relative permeability of the stator iron due the presence of armature reaction; (a) $i_{d}=I_{\max }$ and $i_{q}=0$; (b) $i_{q}=I_{\max }$ and $i_{d}=0$.

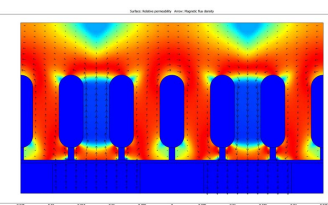

(a)

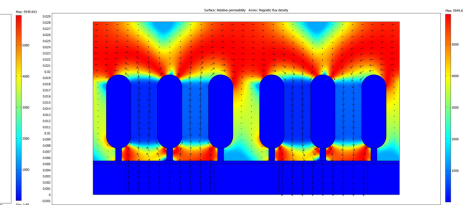

(b)
Fig. 10. Relative permeability of the stator iron due the presence of armature reaction and PM flux; (a) $i_{d}=I_{\max }$ and $i_{q}=0$; (b) $i_{q}=I_{\max }$ and $i_{d}=0$.

The influence of the saturation level in $d(q)$ axis inductances is analyzed by computing the linkage fluxes considering both contributions, armature reaction and PM. Then, the linkage flux in the $d(q)$ axis due to armature reaction under saturation levels in load condition, $\lambda_{\operatorname{Id}(q)}$, is evaluated by the difference between the linkage fluxes in the phase $a$, where both sources are present, $\lambda_{a, m I}$, and 
where is only present the magnetic flux from PM, $\lambda_{a, m}$, from which

$$
L_{s d(q)}=\frac{\lambda_{I d(q)}}{I_{d(q)}}=\frac{\left|\lambda_{a, m}-\lambda_{a, m I}\right|}{I_{\max }}
$$

with phase $a$ axis coincident with $d(q)$ axis, for longitudinal (transversal) synchronous inductances, respectively.

If the analysis is conducted with magnetizing armature reaction, $\lambda_{a, m}<\lambda_{a, m I}$, else, with demagnetizing armature reaction, $\lambda_{a, m}>\lambda_{a, m I}$.

In the machine configuration under analysis, the flux in the $q$ axis follows a path through two teeth with a high saturation level (low permeability), while the flux path in the $d$ axis involves only one tooth under saturation. From this analysis, it is expected a higher influence of the iron saturation level in $L_{s q}$ than in $L_{s d}$.

The results obtained show a reduction about $3 \%$ for the longitudinal synchronous inductance and a higher dependence for transversal synchronous reactance, up to $16 \%$.

\section{E. No-load electromotive force}

The no-load electromotive force (EMF) is computed from the derivative with respect to time of the linkage flux per phase, due to the PM, for incremental positions of the rotor regarding the stator frame. Fig. 11 presents the linkage flux in one phase of the machine computed for several rotor positions and also the reconstructed wave form, considering the main co-sine coefficients from the FFT.

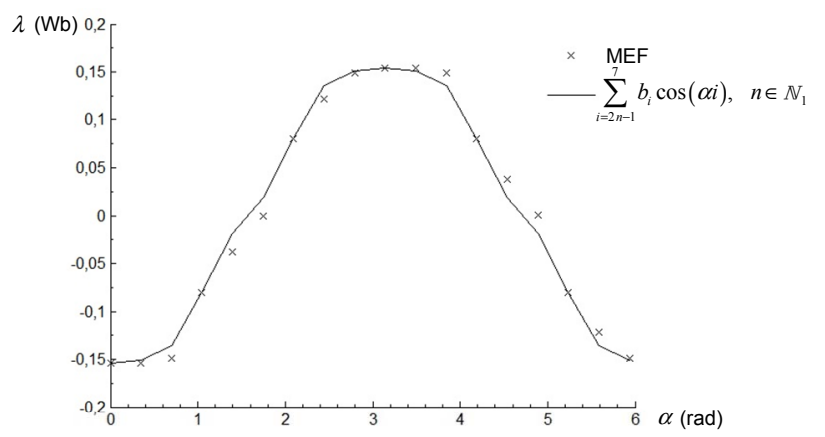

Fig. 11. Linkage flux in one phase of the machine, regarding rotor position ( $\alpha$ in electrical rad).

For a constant rotation speed, $\omega_{r}$, such that $\omega=p \omega_{r}=d \alpha / d t$, EMF per phase and per stator of the machine is computed from

$$
e(\alpha)=\frac{d \lambda(\alpha)}{d \alpha} \frac{d \alpha}{d t}=\omega \frac{d \lambda(\alpha)}{d \alpha}=-\omega \sum_{i=2 n-1}^{7} b_{i} \sin (\alpha i), \quad n \in \mathbb{N}_{1}
$$

The obtained wave form is shown in Fig. 12 (a), along with the fundamental wave form, and its harmonic content is presented in Fig. 12 (b).

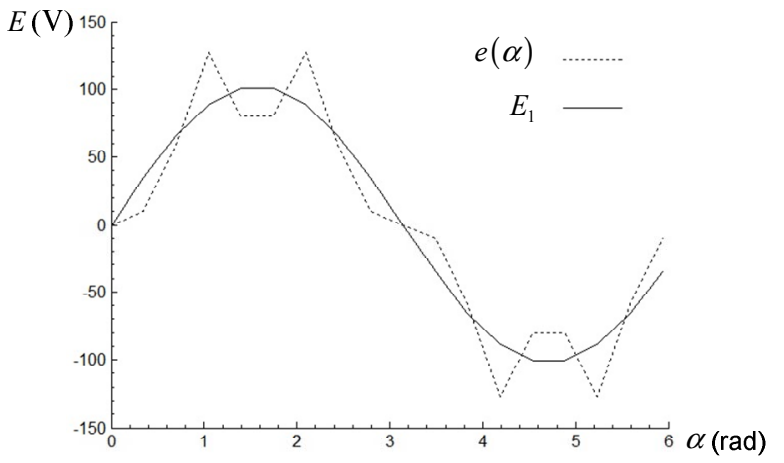

(a)

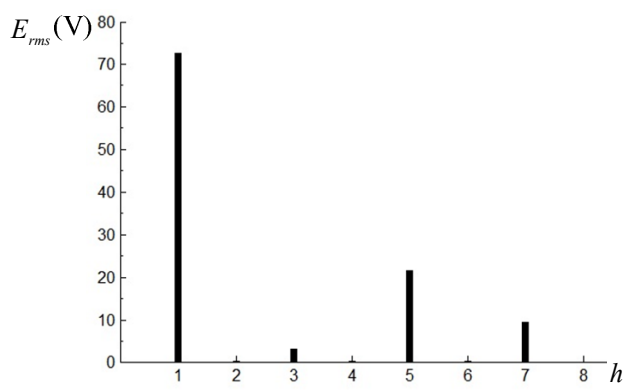

(b)

Fig. 12. (a) Phase-to neutral no-load EMFand (b) its harmonic content.

\section{PRototype Machine AND Test Results}

The validation of the design procedure was accomplished through experimental tests of a prototype machine. The AFPM prototype machine, experimental setup and obtained results are presented in this section. It should be noted that the design procedure does not include any optimization technique and that FE model results previously reported are per stator.

\section{A. AFPM prototype machine}

The AFPM multi-pole machine prototype is a doublesided with internal rotor structure and slotted stators, shown in Fig. 13.

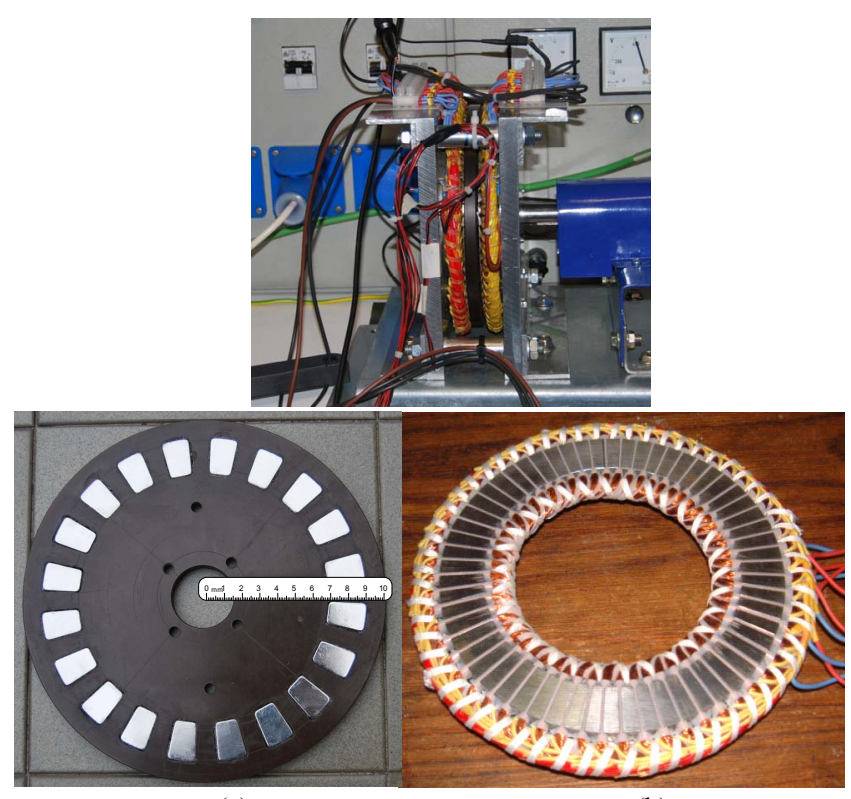

(a)

(b)

Fig. 13. AFPM multi-pole machine prototype (double-sided with internal rotor structure). (a) Rotor disc and (b) one stator. 
Stator rings are from silicon steel sheet in a spiral arrangement, i.e. laminations are in the radial direction (Fig. 13 (a)). The three-phase windings of the two stators are connected in series and the star connection is used to avoid circulating currents.

The inner rotor consists in a holed reinforced thermoset plastic sheet where PM are buried in an axially magnetized configuration (Fig. 13 (b)). Compared to the surface mounted permanent magnets in a non-holed rotor disk, this solution involves the machination and the manipulation of half magnet pieces. The chosen support material is well suited for moderate to high-temperature applications but it is very brittle. The machination of the material to open holes where the PM were placed and glued, turned out to be a difficult task.

Axially magnetized trapezoidal-shaped permanent magnets $\mathrm{NdFeB}$ are used to accomplish the excitation system. Considering the estimated temperature rise of the machine obtained from the thermal model, grade $\mathrm{N} 35 \mathrm{SH}$ was chosen in order to guarantee the remanent magnetic flux density of $1,12 \mathrm{~T}$ used in the design procedure.

\section{B. Experimental results}

The AFPM machine was tested as generator, driven by an induction motor fed by an inverter (Fig. 14). Several tests were performed for the generator under no-load and load conditions.

From a no-load test, the obtained EMF is depicted in Fig. 15 (a). The experimental wave form compared with the one obtained from FE model, through their harmonic content is shown in Fig. 15 (b). The obtained error for the EMF rms value is $11,8 \%$ and for its fundamental component is $8,4 \%$, which is considered acceptable.

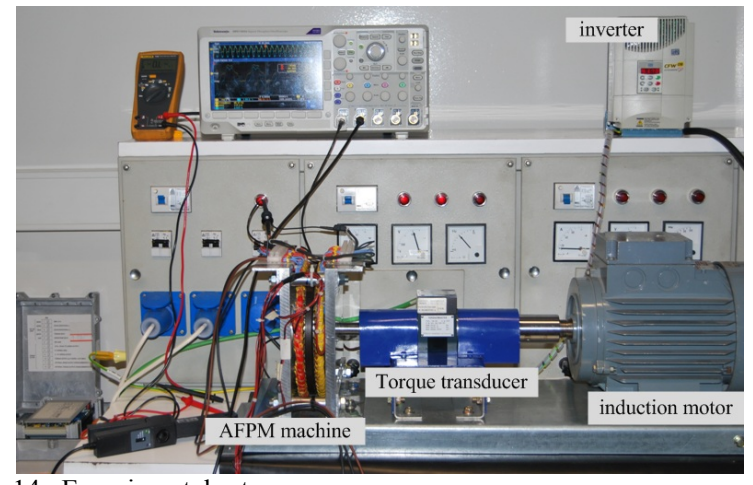

Fig. 14. Experimental setup.

Regarding load tests with resistive load for two different speeds, the voltage and output power versus current are reported in Fig. 16.

Machine losses and efficiency of the machine are depicted in Fig. 17. Resistive losses are calculated through the measured resistance per phase at the reference temperature of the machine and the remaining power losses, iron, mechanical and additional losses, are evaluated using the measured input power, to which the output power and the resistive losses are subtracted.

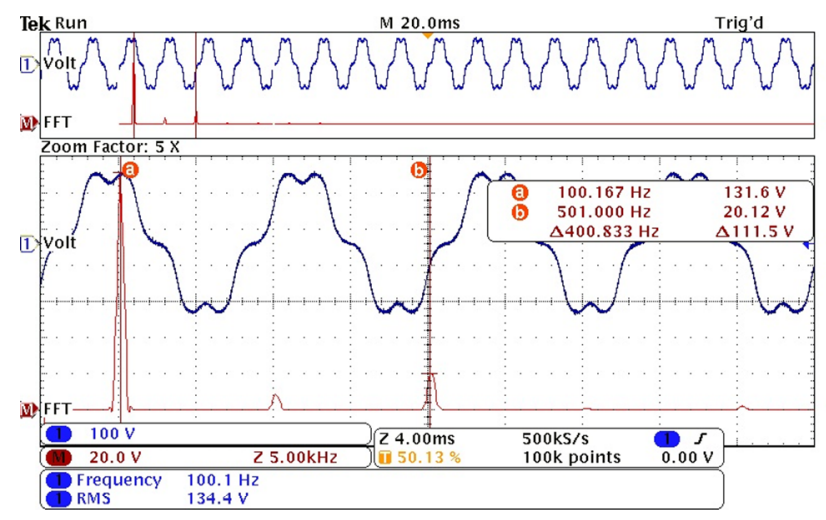

(a)

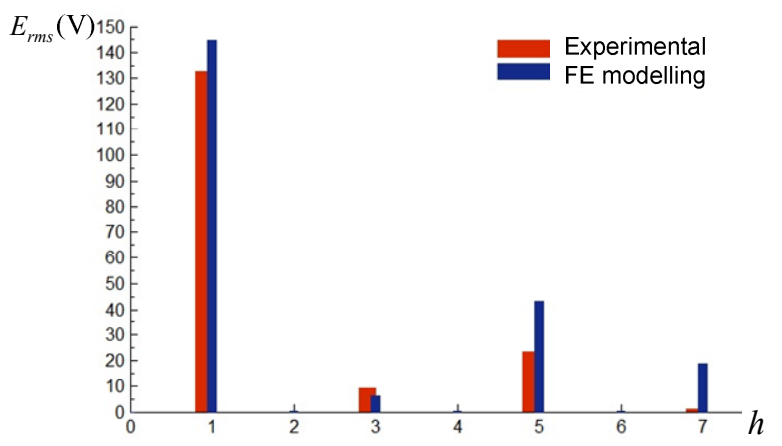

(b)

Fig. 15. (a) Experimental phase to neutral no-load voltage wave form; (b) harmonic content of the FE model and experimental phase to neutral noload voltage.

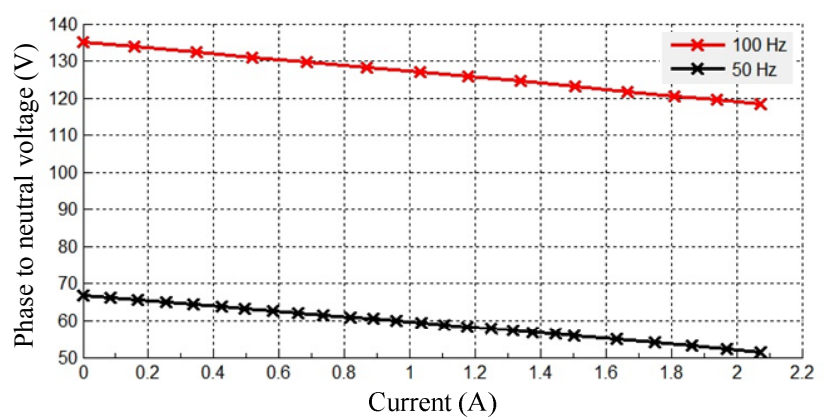

(a)

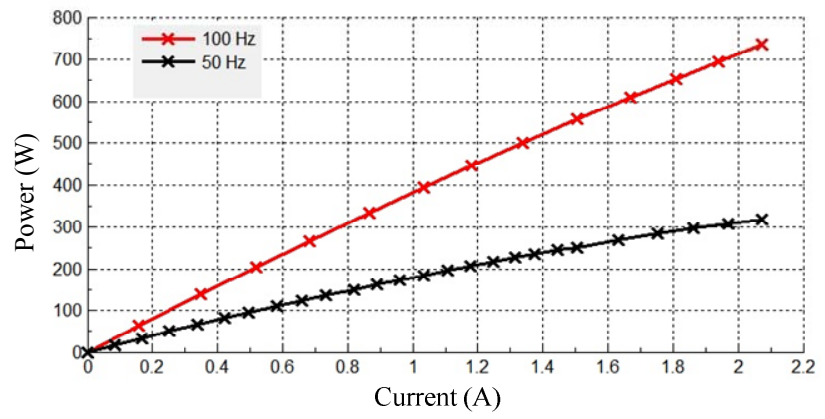

(b)

Fig. 16. (a) Phase to neutral voltage and (b) output power, versus current, for two different speeds. 


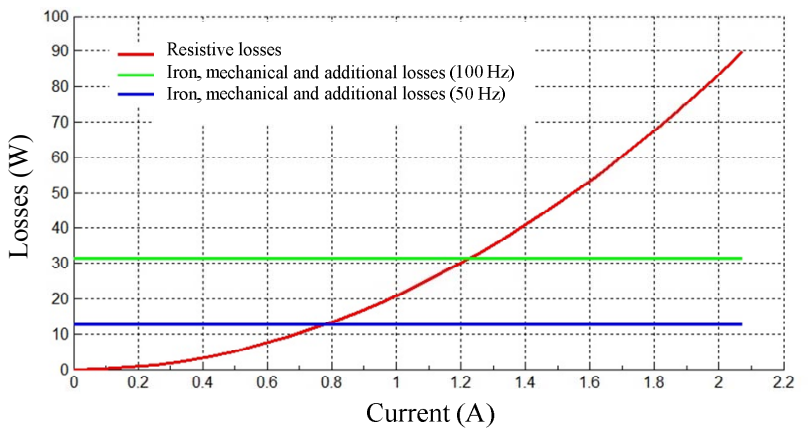

(a)

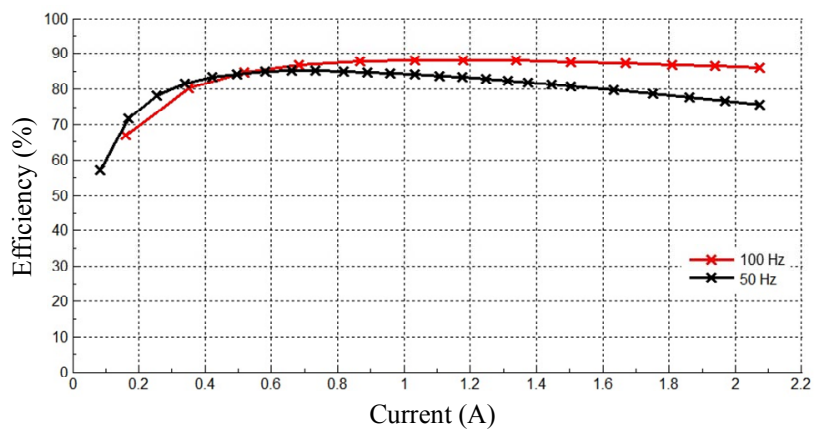

(b)

Fig. 17. (a) Losses and (b) efficiency, versus current, for two different speeds.

Experimental determination of the inductances led to values of $14,3 \mathrm{mH}$, for the $d$ and $q$ axis. From this result, it is not evident the magnetic anisotropy in the experimental prototype. Experimental inductances are in agreement with the ones obtained by the FE model, with an error of $2,8 \%$.

\section{CONCLUSIONS}

This paper presented a comprehensive approach to the FE-aided electromagnetic design of a multi pole doublesided AFPM machine with internal rotor, suited for low speed applications. The implemented FE model routine is comprised in a wider coupled electromagnetic-thermal design procedure. The evaluation of the FE model of the adopted structure was performed through experimental validation of a prototype machine. Experimental results are in good agreement with the simulated ones.

\section{REFERENCES}

[1] K. Sitapati and R. Krishman, "Performance Comparisons of Radial and Axial Field, Permanent-Magnet, Brushless Machines," IEEE Transactions on Industry Applications, vol. 37, pp. 1219-1226, September/October, 2001.

[2] A. Ferreira, A. M. Silva, and A. F. Costa, "An Axial Flux Permanent Magnet Synchornous Genarator for a Gearless Wind Energy System," in 20th International Congress on Condition Monitoring and Diagnostic Engineering Management, COMADEM, Faro, Portugal, 13-15 June, 2007, pp. 115-123.

[3] A. P. Ferreira and A. F. Costa, "Efficient Pole-Arc Coefficients for Maximum No Load Flux Linkage in Axial Flux Permanent Magnet Machines," in 8th IEEE International Symposium on Diagnostics for Electrical Machines, Power Electronics and Drives - SDEMPED 2011, Bologna, Italy, 5-8 September, 2011.

[4] Y. Chen, "Novel Design Configurations for Permanent Magnet Wind Generators," Ph.D., Clarkson University, 2004.
[5] J. F. Gieras, R.-J. Wang, and M. J. Kamper, Axial Flux Permanent Magnet Brushless Machines: Kluwer Academic Publishers, 2004.

[6] J. F. Gieras and N. Bianchi, "Electric Motors for Light Traction," EPE Journal, vol. 14, pp. 12-23, February, 2004.

[7] H. Shute, J. Mallinson, D. Wilton, and D. Mapps, "One-Sided Fluxes in Planar, Cylindrical, and Spherical Magnetized Structures," IEEE Transactions on Magnetics, vol. 36, pp. 440-451, August, 2002.

[8] A. P. Ferreira and A. F. Costa, "Thermal Analysis of an Axial Flux Permanent Magnet Machine," in XXth International Conference on Electrical Machines (ICEM'2012), Marseille, France, 2-5 September, 2012.

[9] N. Rostami, M. R. Feyzi, J. Pyrhonen, A. Parviainen, and M. Niemela, "Lumped-Parameter Thermal Model for Axial Flux Permanent Magnet Machines," IEEE Transactions on Magnetics, vol. 49, pp. 1178-1184, March, 2013.

[10] T. F. Chan and L. L. Lai, "An Axial-Flux Permanent-Magnet Synchronous Generator for a Direct-Coupled Wind-Turbine System," IEEE Transactions on Energy Conversion, vol. 22, pp. 8694, March, 2007.

[11] C. Boccaletti, P. Di Felice, L. Petrucci, and E. Santini, "A Mathematical Model of Axial Flux Disc Machines," in International Conference on Power Engineering, Energy and Electrical Drives, 2009, POWERENG '09, 18-20 March, 2009, pp. 66-71.

[12] O. d. 1. Barriere, H. Ben Ahmed, M. Gabsi, and M. LoBue, "TwoDimensional Analytical Airgap Field Model of an Inset Permanent Magnet Synchronous Machine, Taking Into Account the Slotting Effect," IEEE Transactions on Magnetics, vol. 49, pp. 1423-1435, April, 2013.

[13] A. Mahmoudi, S. Kahourzade, N. A. Rahim, and W. P. Hew, "Design, Analysis, and Prototyping of an Axial-Flux Permanent Magnet Motor Based on Genetic Algorithm and Finite-Element Analysis," IEEE Transactions on Magnetics, vol. 49, pp. 1479-1492, April, 2013.

[14] A. Ferreira, A. M. Silva, and A. F. Costa, "Prototype of an Axial Flux Permanent Magnet Genarator for Wind Energy Systems Applications," in 12th European Conference on Power Electronics and Applications, EPE 2007, Aalborg, Denmark, 2-5 September, 2007.

[15] A. P. Ferreira and A. F. Costa, "Direct Driven Axial Flux Permanen Magnet Generator for Small-Sclale Wind Power Applications," in International Conference on Renewable Energies and Power Quality, ICREPQ'11, Las Palmas de Gran Canaria, 13-15 April, 2011.

[16] F. Magnussen, P. Thelin, and C. Sadarangani, "Performance Evaluation of Permanent Magnet Synchronous Machines with Concentrated and Distributed Windings Including the Effect of Field Weakening," in International Conference on Power Electronics, Machines and Drives (PEMD 2004), 31 March-2 April, 2004, pp. 679-685.

[17] COMSOL. (2013, December, 2013). COMSOL Multiphysics. Available: http://www.comsol.com/products

\section{BIOGRAPHIES}

Ângela P. Ferreira received the Ph.D. degree in Electrical and Computer Engineering from the Faculty of Engineering of the Oporto University, Portugal, in 2012. Since 1997, she has been with the Polytechnic Institute of Bragança, where she is currently a Professor in the Department of Electrical Engineering, School of Technology and Management. Her research interests are focused on design, modelling and optimization of novel permanent magnet machines.

Artur F. Costa received the Ph.D. degree in Electrical and Computer Engineering from the Faculty of Engineering of the Oporto University, Portugal, in 1991. Since then, he joined the Department of Electrical and Computer Engineering of the same institution where he is currently a researcher and lecturer. His research interests include electrical machinery and energy efficiency. 